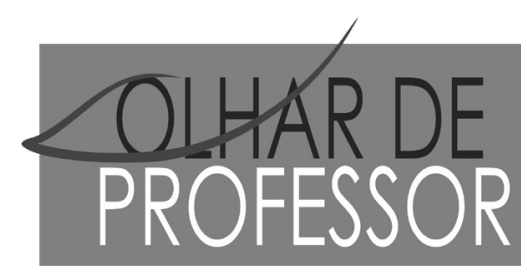

DOI: 10.5212/OLHARPROFR.v.2112.0006

\title{
IMAGENS QUE SE MOVEM - PRODUÇÃO DE STOP MOTION COMO ESTRATÉGIA NA SENSIBILIZAÇ̃̃O DE MULTIPLICADORES PARA PROMOÇ̃̃O DA SAÚDE COM CIENCIARTE
}

\author{
MOVING IMAGES - PRODUCTION OF STOP MOTION AS A STRATEGY IN THE AWARENESS OF \\ MULTIPLICATORS FOR THE PROMOTION OF HEALTH WITH ARTSCIENCE \\ IMÁGENES QUE SE MUEVEN - PRODUCCIÓN DE STOP MOTION COMO ESTRATEGIA PARA LA \\ SENSIBILIZACIÓN DE MULTIPLICADORES PARA PROMOCIÓN DE LA SALUD CON CIENCIARTE
}

\author{
SHEILA SOARES DE ASSIS \\ JURANIR BADARÓ ** \\ MARCELO DE OLIVEIRA MENDES ${ }^{\text {*t }}$ \\ TANIA ARAÚJO-JORGE
}

\begin{abstract}
Resumo: Tuberculose, dengue, zika, chikungunya e febre amarela são doenças que se apresentam como um grande desafio para a saúde pública e demandam participação popular para o seu controle, o que consiste em um ponto nevrálgico contemporâneo. A convergência dos campos da Ciência e da Arte (CienciArte) proporciona a ampliação dos horizontes de percepção da leitura do mundo e uma interpretação multifacetada na busca para a resolução criativa de questões sociais. Realizamos oficinas de CienciArtevisando a produção de animações do tipo stop motion para a formação de multiplicadores para o controle de agravos e promoção da saúde. A análise das imagens produzidas pelos participantes e do seu processo educativo evidenciou que a proposta estimulou o trabalho em grupo, sensibilizou os integrantes das oficinas para a participação social e a elaboração de estratégias que dialoguem com a população de forma mais próxima. O processo criativo proporcionado aguçou a escuta e o olhar ampliado para o tema de interesse. Mas as produções visuais desenvolvidas pelos participantes das oficinas ainda guardam fragmentos de processos educativos e comunicacionais de estratégias padronizadas e tradicionais que desafiam as estratégias mais inovadoras.
\end{abstract}

Palavras-chave: Doenças negligenciadas. Educação em Saúde. Criatividade.

Abstract: Tuberculosis, dengue, zika, chikungunya and yellow fever are diseases that present a great challenge to public health. Social involvement is a contemporary critical point for their control. The convergence of the fields of Science and Art (ArtScience) provides the broadening of the horizons of the perception of the world's reading and a multifaceted interpretation in the search for the creative resolution of social issues. We held ArtScience workshops aiming the production of stop motion animations for the formation of multipliers for hazard control and health promotion. The educational process analysis and the images produced by the participants showed that the proposal stimulated group work, sensitized the members of the workshops for social involvement and the elaboration of strategies that more closely dialogue with the population. The creative process provided improved

\footnotetext{
${ }^{*}$ Mestre e doutora em Ciências pelo Instituto Oswaldo Cruz; Pós doutoranda do Programa de Pós Graduação em Ensino em Biociências e Saúde e vinculada ao Laboratório em Inovações em Terapias, Ensino e Bioprodutos (LITEB) - http://lattes.cnpq. br/7169855766420552

${ }^{* *}$ Especialista em Ciência, Arte e Cultura na Saúde pelo Instituto Oswaldo Cruz - http://lattes.cnpq.br/8541409466976610

*** Arte-Educador da Fundação Oswaldo Cruz, Especialista em Ciência, Arte e Cultura na Saúde pelo Instituto Oswaldo Cruz, Mestrando em Ensino em Biociências e Saúde pelo Instituto Oswaldo Cruz http://lattes.cnpq.br/4276800184312895

${ }^{* * * *}$ Doutora em Ciências pela Universidade Federal do Rio de Janeiro (UFRJ); coordenadora do Programa de Pós Graduação em Ensino em Biociências e Saúde e Pesquisadora titular em Saúde Pública, chefe do Laboratório de Inovações em Terapias, Ensino e Bioprodutos (LITEB) - http://lattes.cnpq.br/1782386890431709
} 
the listening and broadened sight to the topic of interest. However, it also indicated that fragments of educational and communicational processes of standardized and traditional strategies are still present in the visual productions developed by workshop participants.

Keywords: Neglected diseases. Health education. Creativity.

Resumen: Tuberculosis, dengue, zika, chikungunya y fiebre amarilla son enfermedades que se presentan como un gran desafío para la salud pública, y demandan participación popular para su control, lo que consiste en un punto neurálgico contemporáneo. La convergencia de los campos de Ciencia y de la Arte (CienciArte) proporciona una ampliación de los horizontes de percepción de la lectura de mundo y una interpretación multifacética en la búsqueda de una resolución creativa de cuestiones sociales. Realizamos talleres de CienciArte proponiendo la producción de animaciones de tipo Stop motion para la formación de multiplicadores para el control de agravantes y promoción de la salud. El análisis de las imágenes producidas por los participantes y de sus procesos educativos evidenció que la propuesta estimuló el trabajo en grupo, sensibilizó a los integrantes de los talleres para la participación social y la elaboración de estrategias que dialoguen con la población de manera más cercana. El proceso creativo vivenciado aguzó la escucha y la mirada ampliada hacia el tema de interés. Pero las producciones visuales desarrolladas por los participantes de los talleres aún guardan fragmentos de procesos educativos y comunicacionales de estrategias estandarizadas y tradicionales que desafían a las estrategias más innovadoras.

Palabras claves: Enfermedades descuidadas. Educación en Salud. Creatividad.

\section{DOENÇAS NEGLIGENCIADAS: QUESTÕES QUE TRANSCENDEM O CAMPO DA SAÚDE}

Mais de um 1 bilhão de pessoas no mundo são acometidas por pelo menos uma doença considerada negligenciada. Essas doenças afetam predominantemente populações de regiões em desenvolvimento e seus reflexos são sentidos em por toda sociedade. (OMS, 2012). Tuberculose e arboviroses como dengue, zika, chikungunya e febre são doenças negligenciadas que afetam a população (OMS, 2017).

Além de investimento em pesquisa de novos fármacos e de planejamento para eficiência em nível das políticas de saúde pública é necessário o desenvolvimento de propostas educativas que estimulem e sensibilizem a população a participar ativamente das ações de controle e de promoção da saúde. (ASSIS, 2017; OMS, 2017). Segundo a OMS, desde 2003 busca-se exceder este padrão voltado à contenção das doenças negligenciadas. Tradicionalmente o modelo adotado era verticalizado e centrado na doença (OMS, 2012), empobrecido em ações de promoção da saúde.

As ações de educação em saúde tradicionalmente empregadas para abordagem das doenças negligenciadas não são efetivas devido à sua verticalização, à natureza não dialógica e à ausência de articulação com a diversidade cultural local. Assim, elas acabam se traduzindo como ações dotadas de regras impositivas prescritas e que não motivam a participação social. (ASSIS, 2012; 2017). Relacionar e abordar os agravos em uma dimensão exclusivamente biológica é insuficiente. É necessário um envolvimento de toda a sociedade para que haja gradativa redução da mortalidade e morbidade ocasionadas por estes agravos (ABC, 2010; OMS, 2012).Portanto, são necessárias propostas educacionaisque tenham como mote a criatividade, a reflexão sobre a realidade e promoção da participação social, bem como a interação entre diferentes atores da esfera pública como profissionais das áreas da saúde e educação.

\section{IMAGENS, CIENCIARTE E INOVAÇÕES EDUCACIONAIS PARA PENSAR A REALIDADE}

As imagens são registro que estão presentes desde o início da humanidade. Joly (1996) destaca que a imagem consiste em um espelho segundo a leitura de um sujeito frente a um objeto. Logo, falar em imagem é considerar que a mesma é um artefato cultural e como tal dotada de história e objeto antropológico (BARBOSA; CUNHA, 2006). Ao falar de imagens é necessário considerar-se seu simbolismo, seja em relação às visões de mundo do emissor ou às percepções de quem as acessa. (JOLY, 1996). Deste modo:

[...] o processo imagético é por essência uma disposição do olhar para um certo conhecimento da mesma maneira que todo trabalho de escrita passa por uma elaboração ficcional: quando 
esta é deliberadamente escolhida e sobretudo enunciada permite que se ponham em evidência as realidades sociais [...] (PIAULT, 2001, p. 151-152).

Além disso, através das imagens estão presentes representações do universo científico, seja para registrar determinadas observações ou para auxiliar na interpretação de fenômenos de distintas naturezas. (JOLY, 1996). A convergência entre os campos da Ciência e da Arte estão presentes desde os primórdios da história. As obras de Michelangelo e de Leonardo da Vinci são a pura expressão sobre esse fato. (SAWADA; ARAÚJO-JORGE; FERREIRA, 2017).

Em abordagens científicas as expressões artísticas são capazes de provocar a empatia sobre temas complexos, estimular a criatividade, subsidiar um melhor entendimento da realidade e reflexão em relação à mesma. (DE MEIS; RUMJANEK, 2004; ROOT-BERNSTEIN et al., 2001; SILER, 2015). CienciArte é o campo de conhecimento que nasce da associação de duas outras grandes áreas (Ciências e Artes). Sobre este campo Araújo-Jorge et al. (2018) reporta que:

Podemos iniciar repensando como surgiram outros campos interdisciplinares, como a biomedicina, a astrofísica, a bioquímica, a físico-química, a bioengenharia, a mecatrônica, ou mesmo a arte-educação, algumas ainda guardando seus conectores. Todas começaram com a disponibilização dos conceitos, métodos e práticas de um campo para o desenvolvimento do outro. Nesse encontro, nenhum dos campos perde sua especificidade, mas ao tratar de temas de interesse comum sob duas ou mais perspectivas diferentes, ambas se enriquecem e contribuem para inovar em soluções para o tema instigante que as uniu. Portanto, o nascer de um novo campo interdisciplinar não extermina os anteriores, mas abre uma nova via, uma nova perspectiva. E é assim que pensamos na perspectiva de que estamos vivendo atualmente a emergência deste novo campo, a CienciArte. (ARAÚJO-JORGE et al., 2018, p. 26).

Reconhecidamente, o campo da CienciArte apresenta de modo inovador a abordagem para temas que devem transcender o olhar disciplinar por meio natureza de associação razão e emoção, abstração, capacidade de transformar, entre outros. (DE MEIS; RUMJANEK, 2004). Ressalta-se que o emprego de propostas colaborativas no âmbito da educação em saúde pode proporcionar maior diálogo na construção compartilhada de representações simbólicas de diferentes sujeitos e seu meio. (ASSIS; SCHALL; PIMENTA, 2013).

Assim sendo, tendo em vista a relevância das doenças negligenciadas, a necessidade de propostas educacionais inovadoras e o potencial manifesto pelo campo da CienciArtepara as práticas educativas, o objetivo do presente estudo foi analisar o processo e os produtos imagéticos produzidos em oficinas de stop motion cujo o mote foram doenças negligenciadas (tuberculose e as arboviroses).

\section{PERCURSO METODOLÓGICO}

A pesquisa possui caráter qualitativo e versa sobre o tema das doenças negligenciadas no âmbito do Programa Saúde na Escola (PSE) em regiões prioritárias do Plano Brasil sem Miséria (BSM). O projeto de pesquisa foi aprovado pelo Comitê de Ética em Pesquisa em Seres Humanos (CEP-IOC/Fiocruz) sob o número 114.584. Apresentaremos os resultados de duas oficinas, a primeira na cidade de Rio Branco (AC) em julho de 2014 e a segunda em fevereiro de 2017 na comunidade de Maguinhos localizada na cidade do Rio de Janeiro (RJ). Ambas as atividades compuseram as ações desenvolvidas no projeto Expedições de Educação e Ciência para o Brasil sem Miséria: Formação continuada para Saúde e Cidadania na Educação Básica” (2012 - 2017) congregando ações de ensino, pesquisa, extensão e fortalecimento da participação popular em locais de interesse. (ASSIS, 2017).

\section{DESCRIÇÃO DAS OFICINAS}

A oficina realizada em Rio Branco ocorreu durante o curso de formação ofertado aos Agentes de Endemias, Agentes Comunitários de Saúde e Agentes de Assistência Social. O curso teve carga horária total de 8 horas (realizado em um único dia e subdividido em dois períodos, manhã e tarde). Na ocasião, 
no período da manhã houve rodas de conversa, sendo a primeira acompanhada da apresentação de vídeos jornalísticos com matérias sobre doenças negligenciadas de interesse local (malária, doença de Chagas e arboviroses). O espaço foi compartilhado com uma exposição oral sobre a tuberculose mediada por uma médica infectologista e uma apresentação sobre a estratégia de CiênciArte, por meio da música popular brasileira, para a promoção da Saúde e a abordagem das doenças negligenciadas. No período da tarde, os participantes do curso foram divididos em dois grupos, um dos quais seguiu com a produção de sequências de imagens para confecção de uma animação tipo stopmotion. Ao todo 34 pessoas, subdivididas em três grupos, participaram da produção dos filmetes de stop motion.

A segunda edição da oficina ocorreu durante o Curso de Formação de Agentes Populares de Saúde e Vigilância Ambiental, realizada em uma tarde. Inicialmente foi feita uma roda de conversa onde foram apresentados vídeos com matérias jornalísticas sobre as arboviroses e em seguida os participantes foram subdivididos em quatro grupos. Cada grupo desenvolveu diferentes sequências de imagens abordando aspectos relativos à temática das arboviroses.

Para produção das animações era solicitado aos participantes que desenvolvessem um roteiro sobre uma determinada situação envolvendo o tema da oficina. Em seguida era necessário desenhar ou realizar colagem de no mínimo 18 cenas. As cenas foram então fotografadas em sequência e posteriormente editadas digitalmente pela mediadora da oficina para construção de filmetes em sistema stop motion. Alternativamente, também foi possível fazer apenas a projeção rápida sequencial das imagens em programa visualizador de imagens, sem a montagem final dos filmetes.

\section{REGISTROS DE CAMPO E INTERPRETAÇÃO DOS RESULTADOS}

Ao compor o trabalho com imagens é necessário considerar que estes são produtos de uma sociedade de história e que sua interpretação não pode ser linear, desconsiderando o seus contextos de produção e de quem os elaborou. (PIAULT, 2001). Assim, ao longo do trabalho de campo foi utilizado pelos pesquisadores um diário para anotação dos eventos e contextualização dos registros a serem interpretados.

Já para interpretação dos achados no campo foi empregada a análise hermenêutica. Esta modalidade de análise tem por finalidade interpretar o que está contido de forma explícita ou implícita no material a ser apreciado. Neste sentido, Minayo (2010) expõe que a hermenêutica se baseia na compreensão do material pelo pesquisador dentro do contexto observado em campo. A análise que se apropria deste olhar não visa somente refletir sobre o que está expresso diretamente, mas busca uma dimensão mais ampla (até subjetiva) que implica em tomar conhecimento e compreender a visão expressa pelo autor.

\section{RESULTADOSE DISCUSSÃO}

\section{NOTAS DE PESQUISA SOBRE AS OFICINAS}

As oficinas foram apresentadas para públicos distintos: a atividade realizada em Rio Branco foi dirigida aos profissionais que atuam no campo da assistência social e da saúde, a atividade realizada no Rio de Janeiro teve como publico jovens e adultos residentes na comunidade de Manguinhos e outras localizadas no seu entorno.

Os integrantes de ambas as oficinas possuíam entre o ensino fundamental completo ao ensino superior e embora pertencessem os públicos diferentes apresentaram produções próximas, principalmente, no que se refere a representação do vetor Aedes aegypti.

Outra questão importante a ser ponderada é que a oficina realizada no Acre permitiu uma abordagem mais ampla em comparação com a que ocorreu no Rio de Janeiro. A atividade realizada no Acre apresentou a abordagem de quatro doenças negligenciadas diferentes (dengue, malária, doença de Chagas e tuberculose). Contudo, para a produção das imagens que constituíram os filmetes de stop motion, os participantes optaram apenas pela dengue e pela tuberculose como conteúdo a ser trabalhado. Tal escolha deveu-se ao reconhecimento desses dois agravos como prioritários em seu território de atuação. O público 
da oficina atuava profissionalmente na capital do Estado que havia experimentado uma grande epidemia de dengue no período próximo à atividade. Além disso, havia participantes pertencentes ao quadro de agentes de assistência social que integravam a equipe do Consultório de Rua que é uma estratégia instituída na Política Nacional de Atenção Primária onde uma equipe multidisciplinar se volta para a atenção à população que se encontra em situação de rua. (BRASIL, 2011). Segundo os participantes a tuberculose é um problema pontual especificamente para esse público, principalmente, devido à dificuldade de continuidade de permanência no tratamento. Zuim e Trajman (2018) investigaram a trajetória terapêutica da população em situação de rua e em tratamento de tuberculose. Ao tratar do tema, as autoras indicaram a necessidade de fortalecimento da empatia entre a equipe multiprofissional que atende a esta população e a necessidade de humanização do tratamento empregado. Nesse sentido, a prática realizada junto aos profissionais de saúde e assistência social em Rio Branco convergiu para que eles pudessem repensar suas práticas e atuação junto à população.

Além disso, o trabalho com oficinas dialógicas se caracterizou com uma estratégia capaz de fomentar a colaboração para trabalhos em grupo e reflexão coletiva frente às questões que estão presentes em seu meio. A este respeito é importante destacar que o produto das oficinas não é resultante de um único indivíduo, mas sim uma elaboração singular desenvolvida a partir da interação. É uma prática que possui corpo coletivo. (SPINK; MENEGON; MEDRADO, 2014). Destaca-se também as possibilidades despertas a partir da atividade realizada. Os participantes das duas oficinas sinalizaram que a estratégia desenvolvida possui o potencial de ser replicada, seja no seu espaço de convívio social ou com o público com o qual trabalham com a finalidade de sensibilizar outros indivíduos para questões emergentes em seu território.

\section{ASPECTOS ABORDADOS NA PRODUCÃ̃O DE IMAGENS}

Um aspecto recorrente na narrativa, e representado nas imagens geradas ao longo da oficina, foi a associação da reprodução do Aedes aegypti com o lixo (Figura 1). Sobral e Sobral (2019) discorreram sobre a importância da coleta de lixo para o impacto negativo na incidência de arboviroses transmitidas por mosquitos do gênero Aedes. Contudo, a narrativa apresentada pelos participantes durante o desenvolvimento da oficina foi de que embora a coleta de lixo seja regular no bairro de Manguinhos a questão fica insolúvel pelo compartilhamento do território com dependentes químicos que se apropriam do espaço destinado para o descarte do lixo. Assim, os moradores acabam por depositar o lixo doméstico no entorno das caçambas de coleta. Nesse sentido, a oficina se configurou como uma importante proposta para a emersão de questões culturais e do cotidiano da comunidade, desconhecida nas ações educativas empregadas para o controle vetorial e prevenção de arboviroses.

Figura 1 - Imagem produzida pelos participantes da oficina realizada em Manguinhos (RJ) associando a reprodução do vetor ao descarte do lixo doméstico

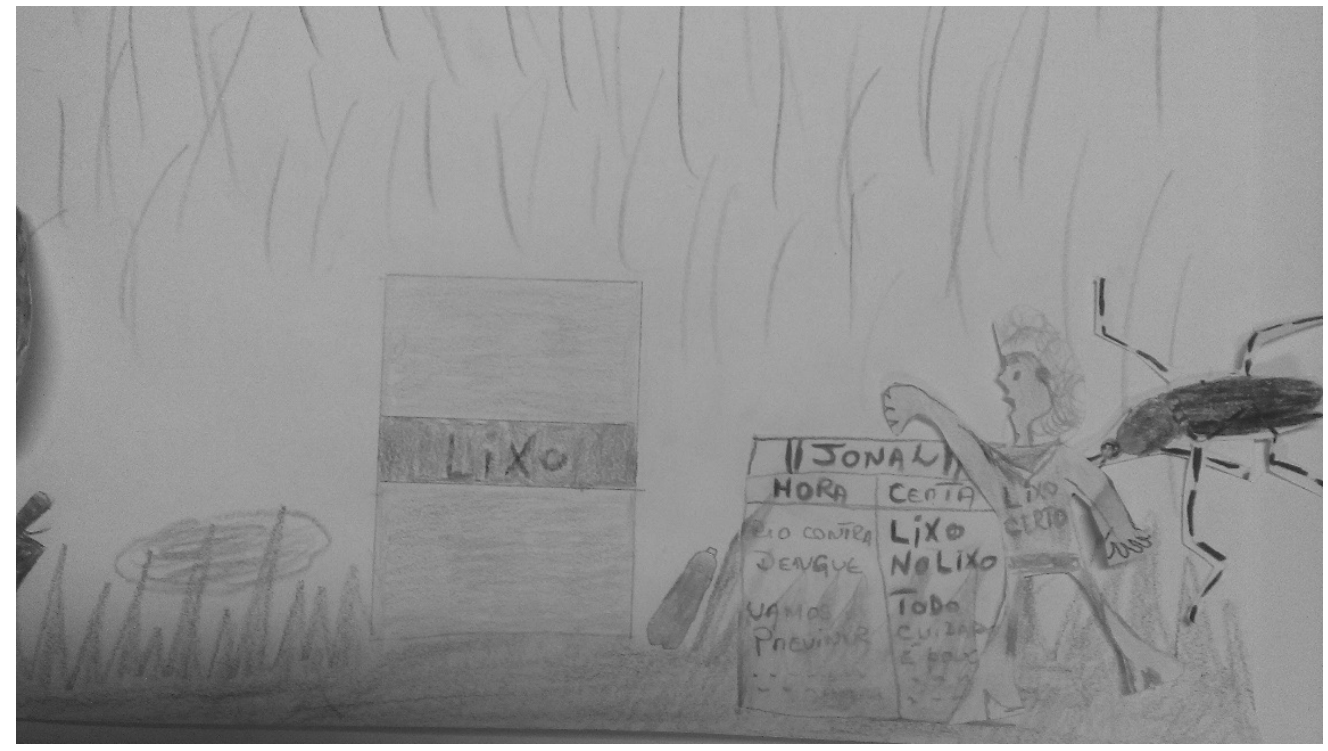

Fonte: Acervo pessoal. 
Além da associação do vetor com o lixo, uma representação recorrente quando se aborda o processo saúde - doença é a associação com a morte. Tal relação foi expressa como o título de um dos filmetes produzidos durante as oficinas (figura 2). Esse tipo de apelo remetendo o vetor/doença à morte é comum em peças de comunicação e informação empregadas em ações de educação em saúde em que se pretende mobilizar a população. (ASSIS, 2012; GAZZINELLI et al., 2005; REIS, 2006). Expressam o exercício da pedagogia do medo, em que o sujeito deve adotar tais medidas a fim de evitar o "mal" representado pela doença/vetor.

O destaque da importância dos profissionais de saúde para o controle e prevenção de arboviroses foi expresso nas imagens produzidas durante as oficinas realizadas em Rio Branco (AC) (Figuras 3 e 4). Em pesquisa realizada com diferentes atores sociais Souza et al. (2018) verificaram que os agentes de endemias entrevistados expressavam a mesma importância. Nas imagens produzidas há ainda o simbolismo de que o profissional é encarregado da resolução do problema encontrado como a infestação vetorial que ocasionou o adoecimento.

Além disso, é interessante notar que as representações do doente enfatizam sempre questões biomédicas. Já em relação ao vetor esteve presente a associação com questões sociais. Essa abordagem diverge da encontrada em materiais educativos impressos e livros didáticos quando abordam a dengue. (ASSIS; SCHALL; PIMENTA, 2013). Esse aspecto é de extrema relevância na medida que revela o potencial da atividade empregada em proporcionar o desenvolvimento de um material que seja produzido pelos profissionais envolvidos nas ações de educação em saúde. Ademais, a atividade desenvolvida se caracterizou como uma oportunidade para que a prática profissional fosse repensada e as possibilidades de envolver a população na produção de recursos de informação e divulgação de modo a incorporar elementos simbólicos que são comumente ignorados em recursos produzidos de forma vertical.

Figura 2 - Associação da reprodução do vetor com o lixo e o emprego de termos alarmistas para abordagem do tema

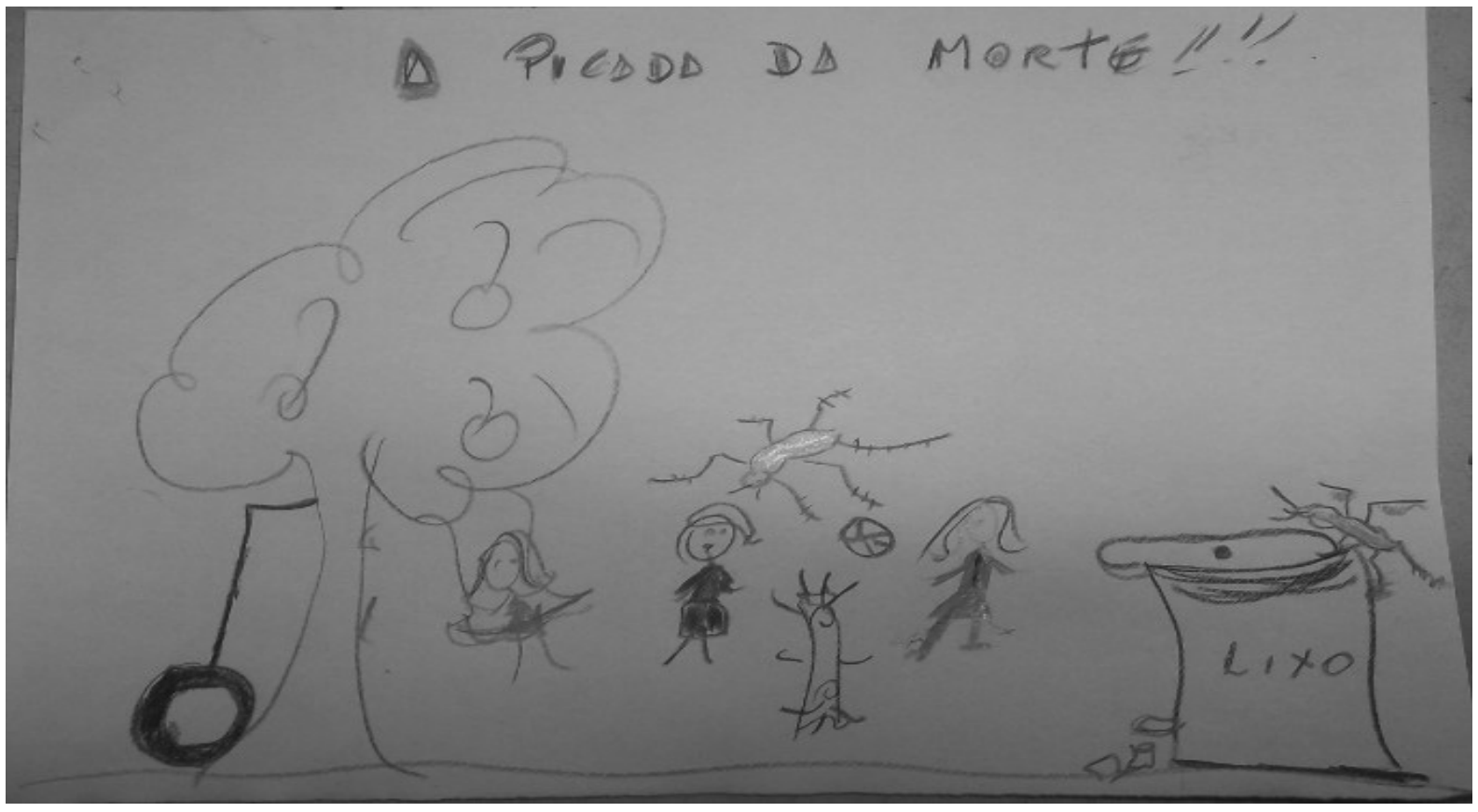

Fonte: Acervo pessoal. 
Figura 3 - Representação visual do profissional de saúde

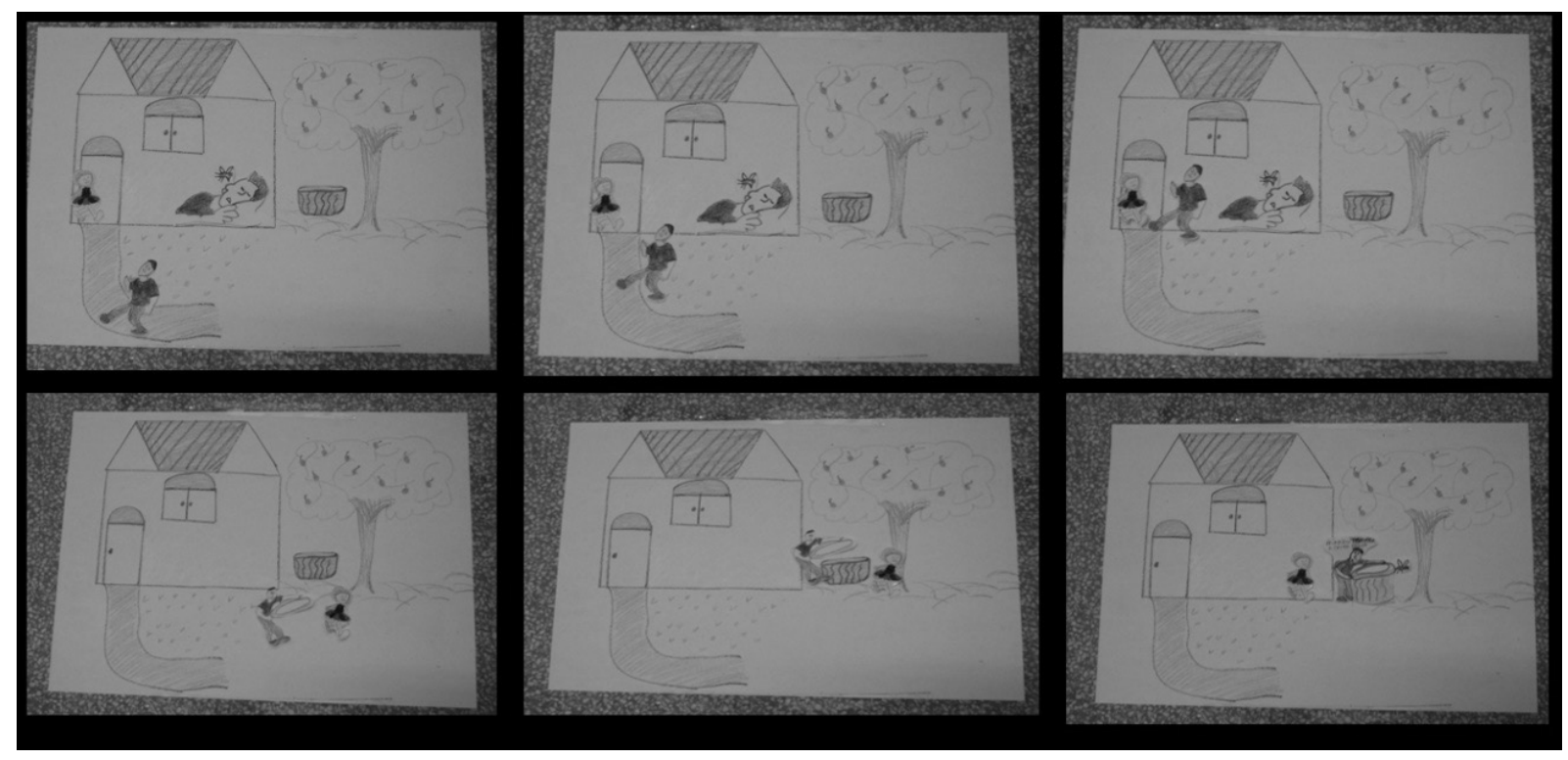

Fonte: Acervo pessoal.

Figura 4 - Agente comunitário de saúde abordando a moradora e vedando a caixa d’água

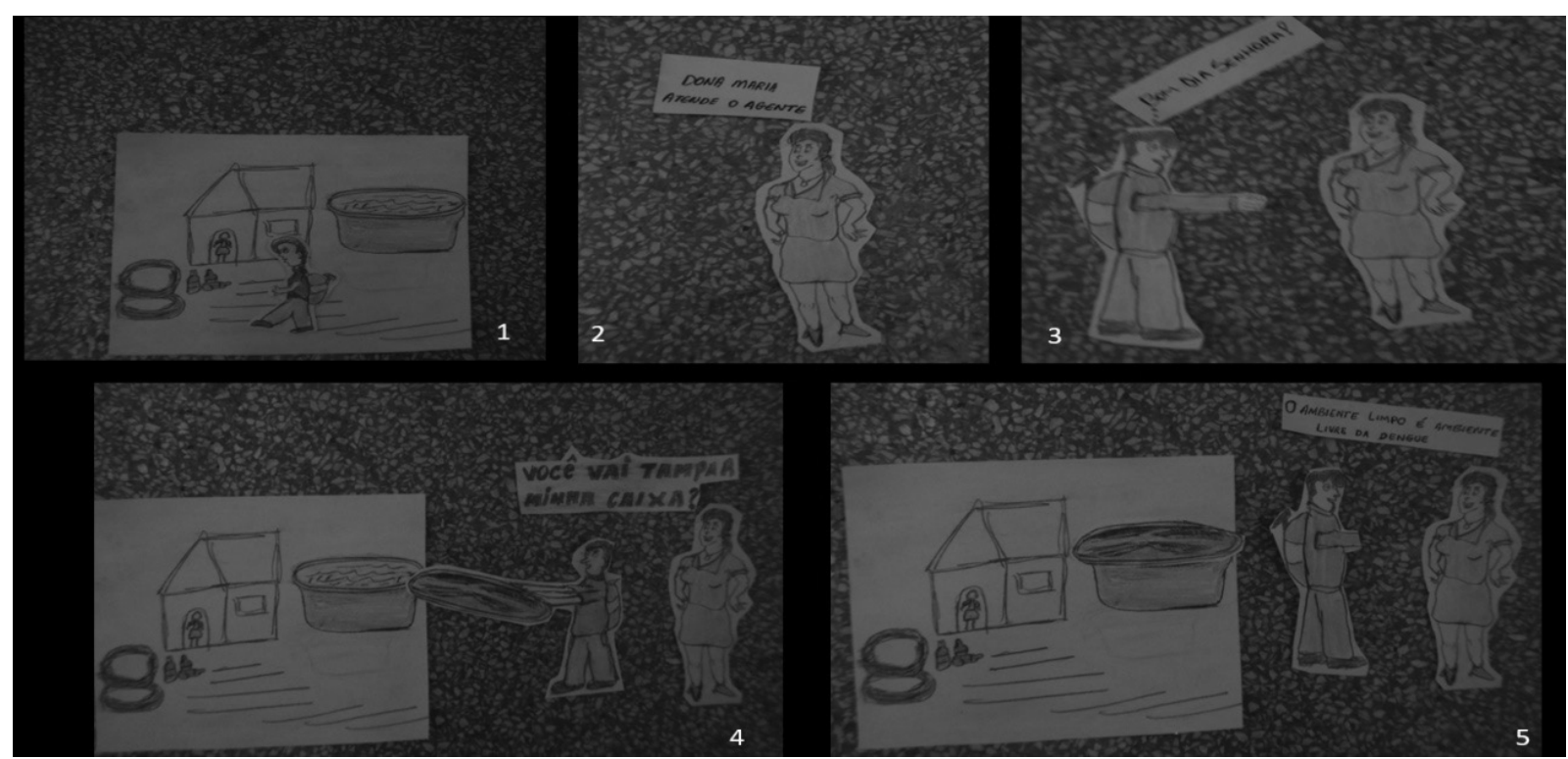

Fonte: Acervo pessoal.

A representação do território foi outro elemento relevante que emergiu nas imagens produzidas pelos participantes da oficina. A caracterização do espaço da comunidade esteve presente de forma proeminente nos desenhos produzidos pelos integrantes do curso de formação realizado em Manguinhos. Tais imagens expressam o sentimento dos participantes de pertencimento ao espaço de modo que detalham construções e aparelhos públicos do Estado característicos da comunidade, bem como as mazelas sociais relacionadas ao abandono por parte do poder público. O espaço para denúncia social é algo peculiar que cabe às diferentes formas de arte. Harrington (2004) reportou que o aspecto de denúncia de forma alguma se sobrepõe ao valor estético do produto artístico. Há ainda o registro de locais que são apresentados com orgulho pela população local como, por exemplo, a escola pública que possui uma piscina olímpica que anteriormente era utilizada também como área de lazer da comunidade ou a estação de trem reformada recentemente (Figuras 5 e 6). 
Figura 5 - Imagem representativa da piscina da escola localizada na comunidade com infestação de Aedes
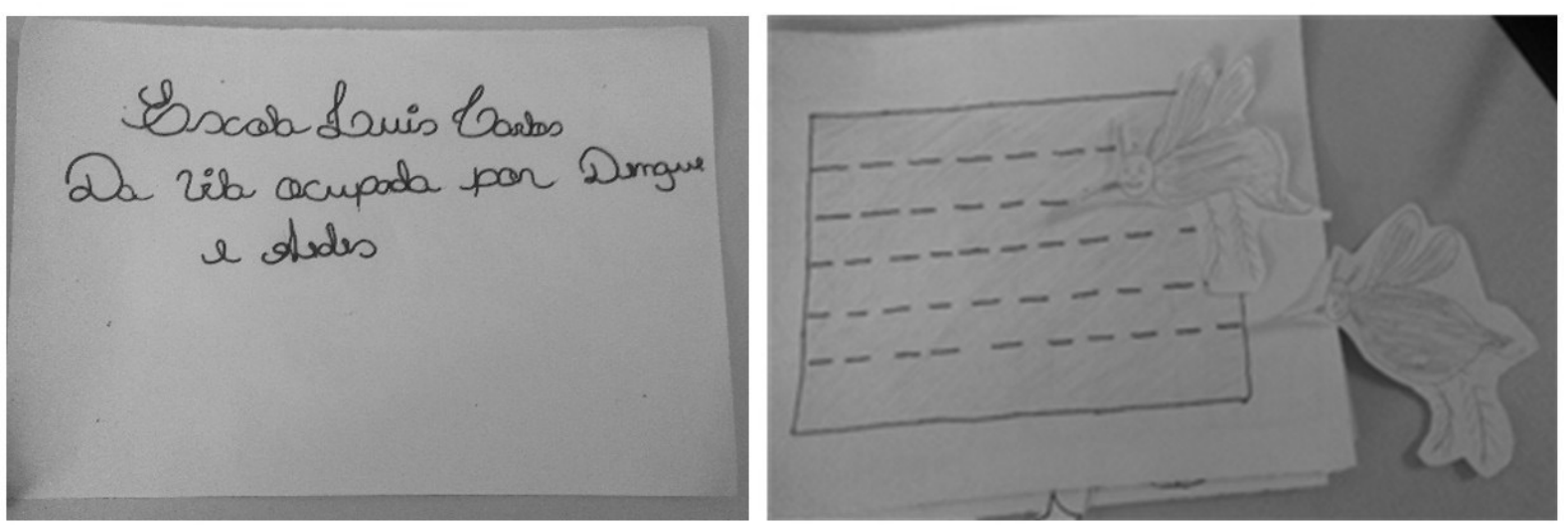

Fonte: Acervo pessoal.

Figura 6 - Figura da estação de ferroviária de Manguinhos (RJ)

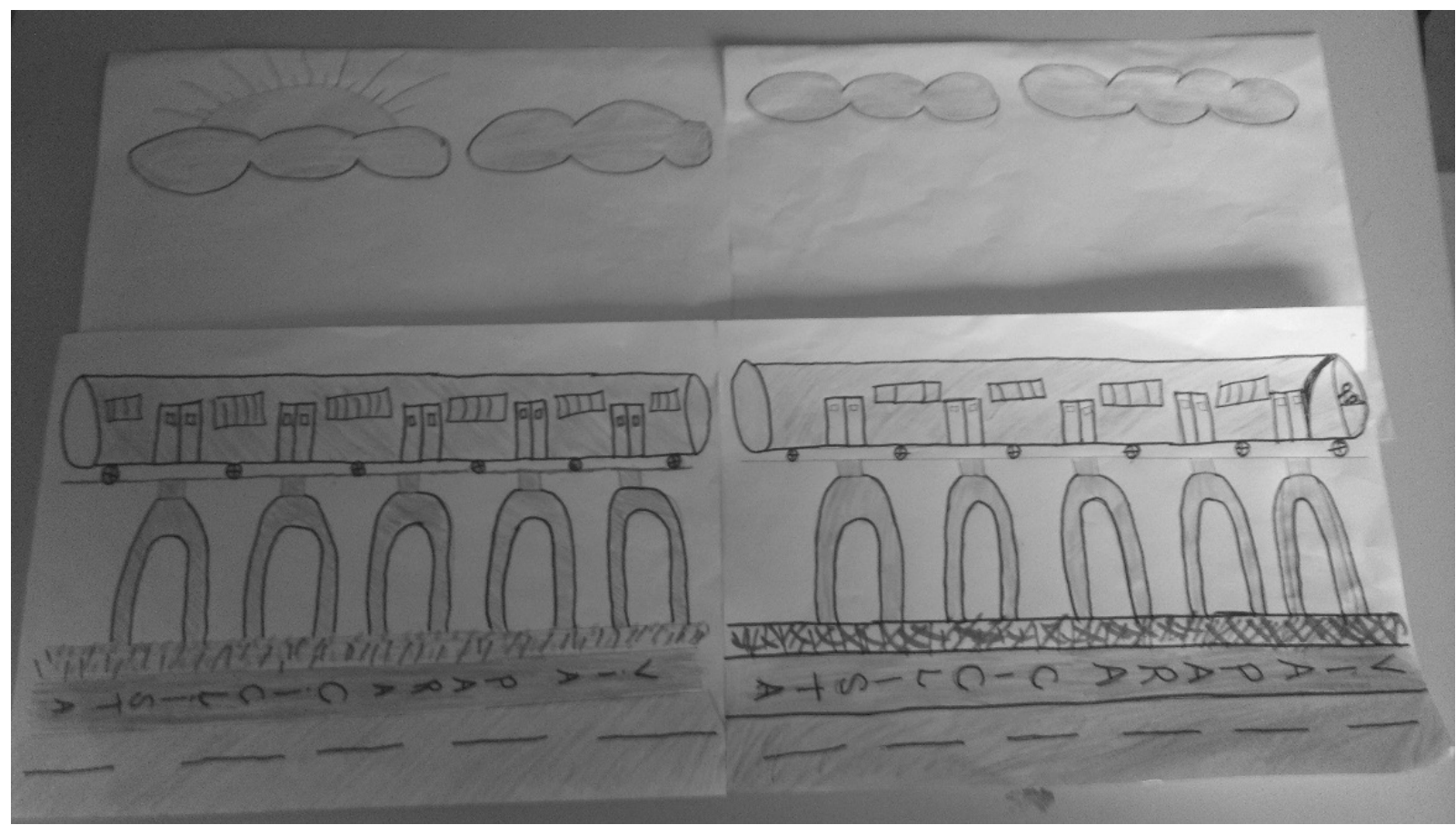

Fonte: Acervo pessoal.

A mobilização popular foi um ponto sensível nas discussões realizadas ao longo da oficina e foi manifesta como uma questão importante nas figuras geradas para as animações. A participação de diversos atores sociais é um aspecto crítico no controle de arboviroses devido à prevalência de focos de criadouros no interior das residências ou na região peridomiciliar. (OMS, 2017). Nas imagens elaboradas durante a atividade chama a atenção o fato de personagens infantis serem representados como os responsáveis por ações de controle a nível local ou difusores de informações (Figuras 7 e 8). Esse tipo de representação converge com a análise realizada em materiais educativos impressos em que o perfil infantil também foi explorado, ora como personagem frágil e susceptível a doença, e ora como indivíduo empoderado que atua como agente de mudança local. (ASSIS; SCHALL; PIMENTA, 2013). 
Figura 7 - Alunos da escola local se mobilizando para a limpeza da piscina

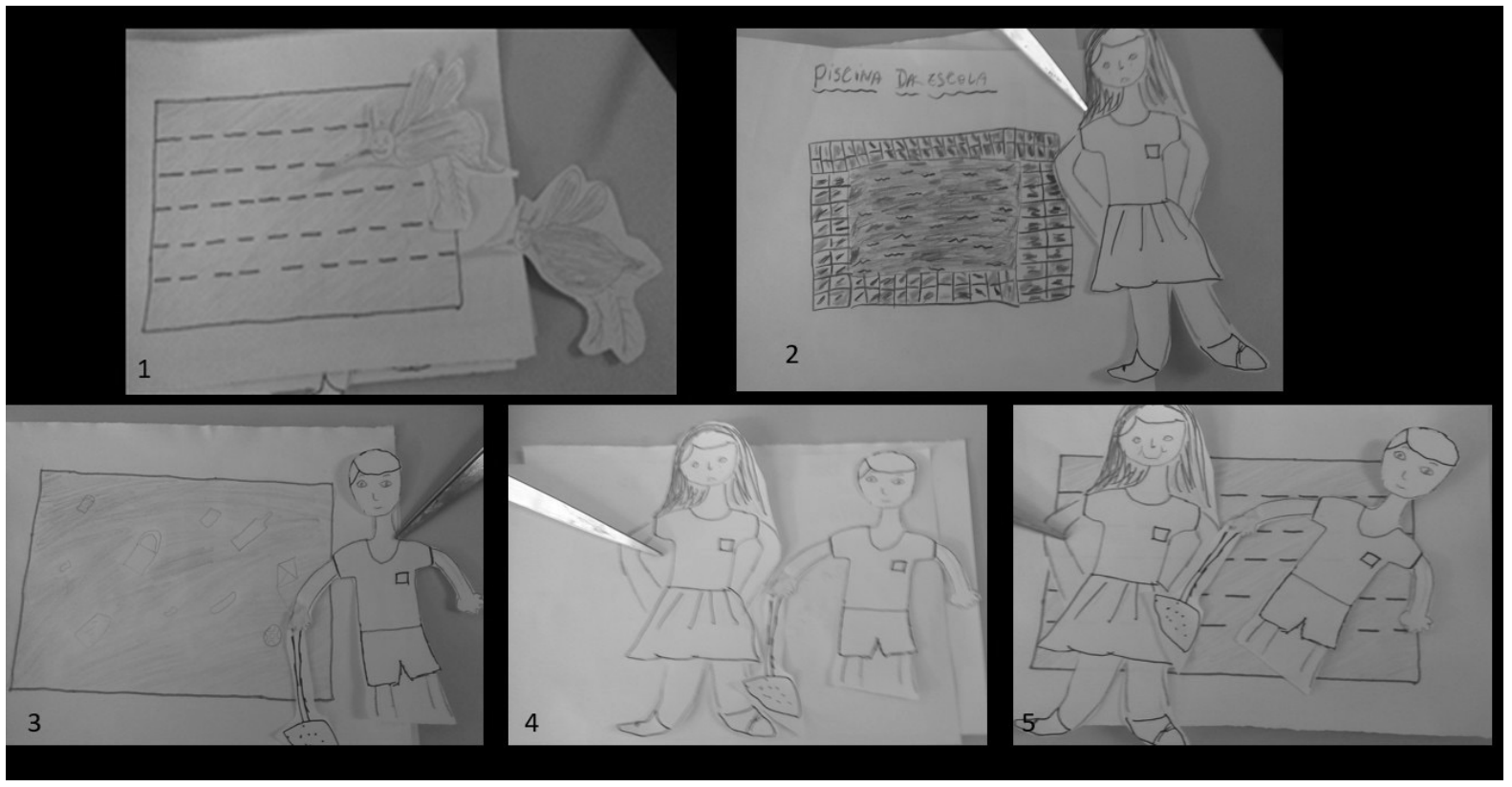

Fonte: Acervo pessoal.

Figura 8 - Criança atuando como agente de mobilização popular na estação de trem da comunidade

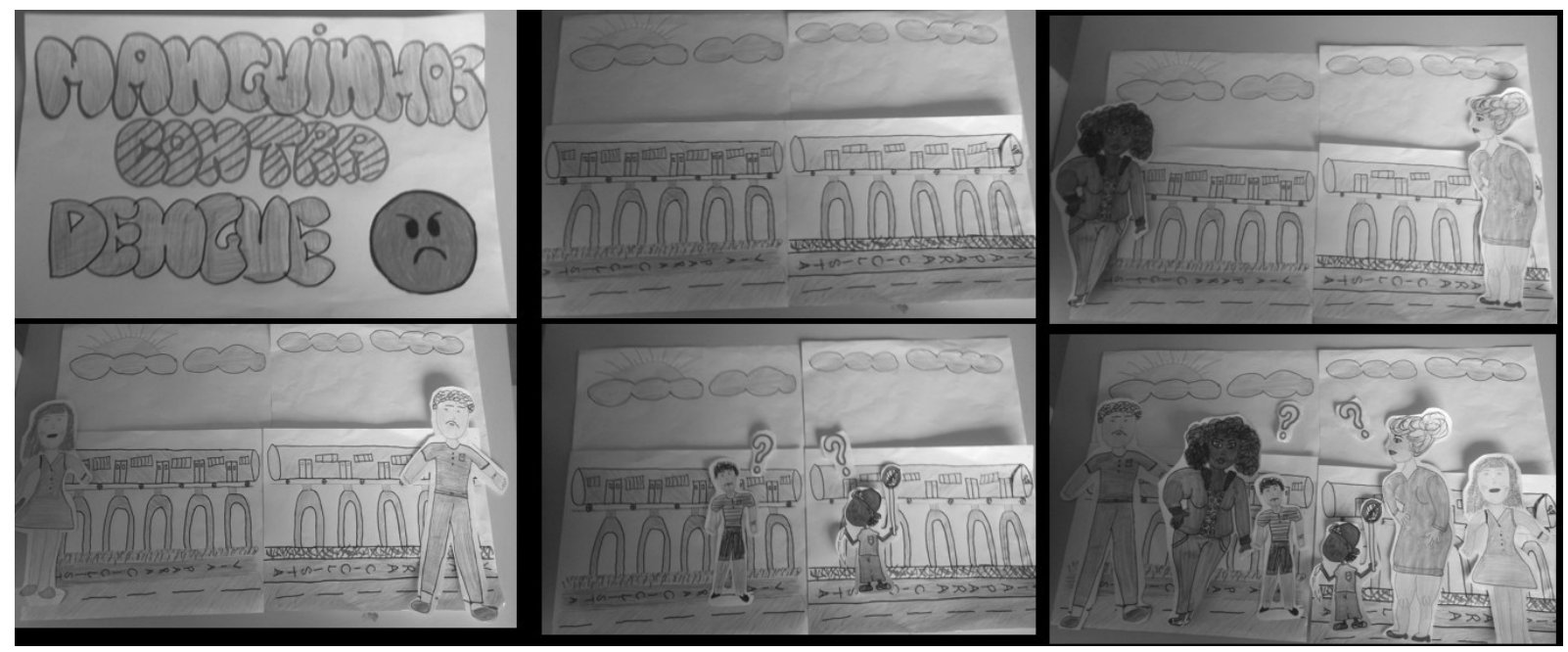

Fonte: Acervo pessoal.

As doenças negligenciadas, de modo geral, são questões complexas e que requerem a atuação integrada de diferentes setores sociais. Tal aspecto ficou evidenciado nas ilustrações produzidas por profissionais de saúde e assistência social. As figuras demonstram a abordagem da equipe de agentes de assistência social ao cidadão em situação de rua. Após verificarem a suspeita de tuberculose o paciente é encaminhado ao atendimento médico em uma Unidade Básica de Saúde (UBS) (Figura 9). A representação é um avanço sobre a reflexão do funcionamento das políticas públicas que visam atender à população. Contudo, tal integração não deve ser um fim em si mesma. É necessário que se supere o modelo compartimentalizado a nível de planejamento e gestão dos serviços. (STANDLEY et al., 2018). 
Figura 9 - Representação do trabalho integrado dos setores de assistência social e saúde para diagnóstico e tratamento da tuberculose.

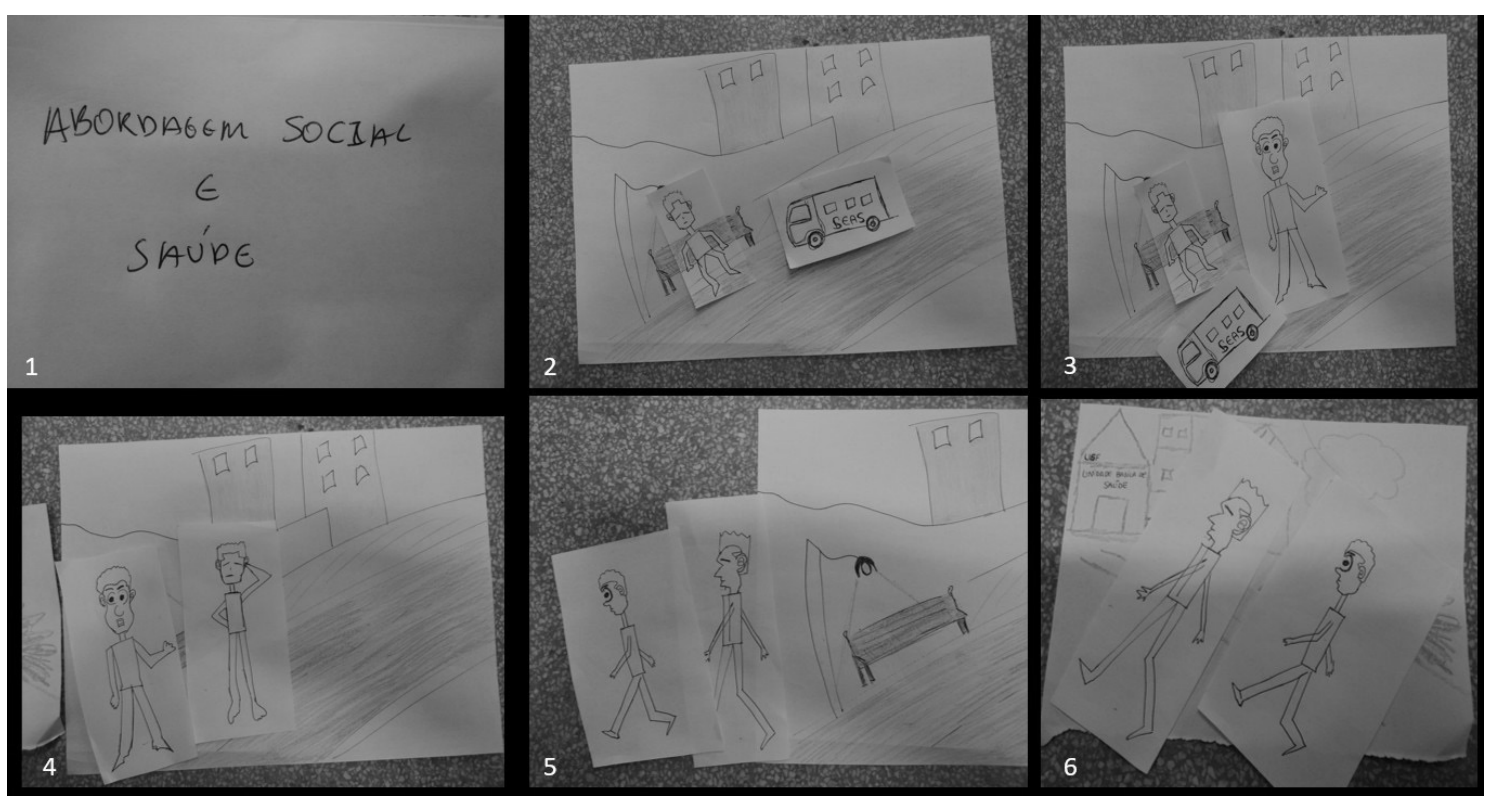

Fonte: Acervo pessoal.

Durante a atividade realizada percebemos que ainda há a presença de um padrão comunicacional que privilegia termos de cunho militarista como, por exemplo, “combate” (Figura 10). Expressões que remetem à guerra não são adequadas para emprego nas ações educativas, visto que estas reservam a característica impositiva e não privilegiam a reflexão. O emprego desse tipo de expressão já foi denunciado em outros trabalhos inclusive ao tratar da dengue. (ASSIS; PIMENTA; SCHALL, 2013). Portanto, ao surgir tal termo durante a oficina foi possível discutir a questão junto aos envolvidos. Deste modo, o olhar sobre a comunicação em saúde foi ampliado via a uma atividade que contemplou o campo da CienciArte.

Figura 10 - “Combate” à dengue - padrão comunicacional com termos não adequados

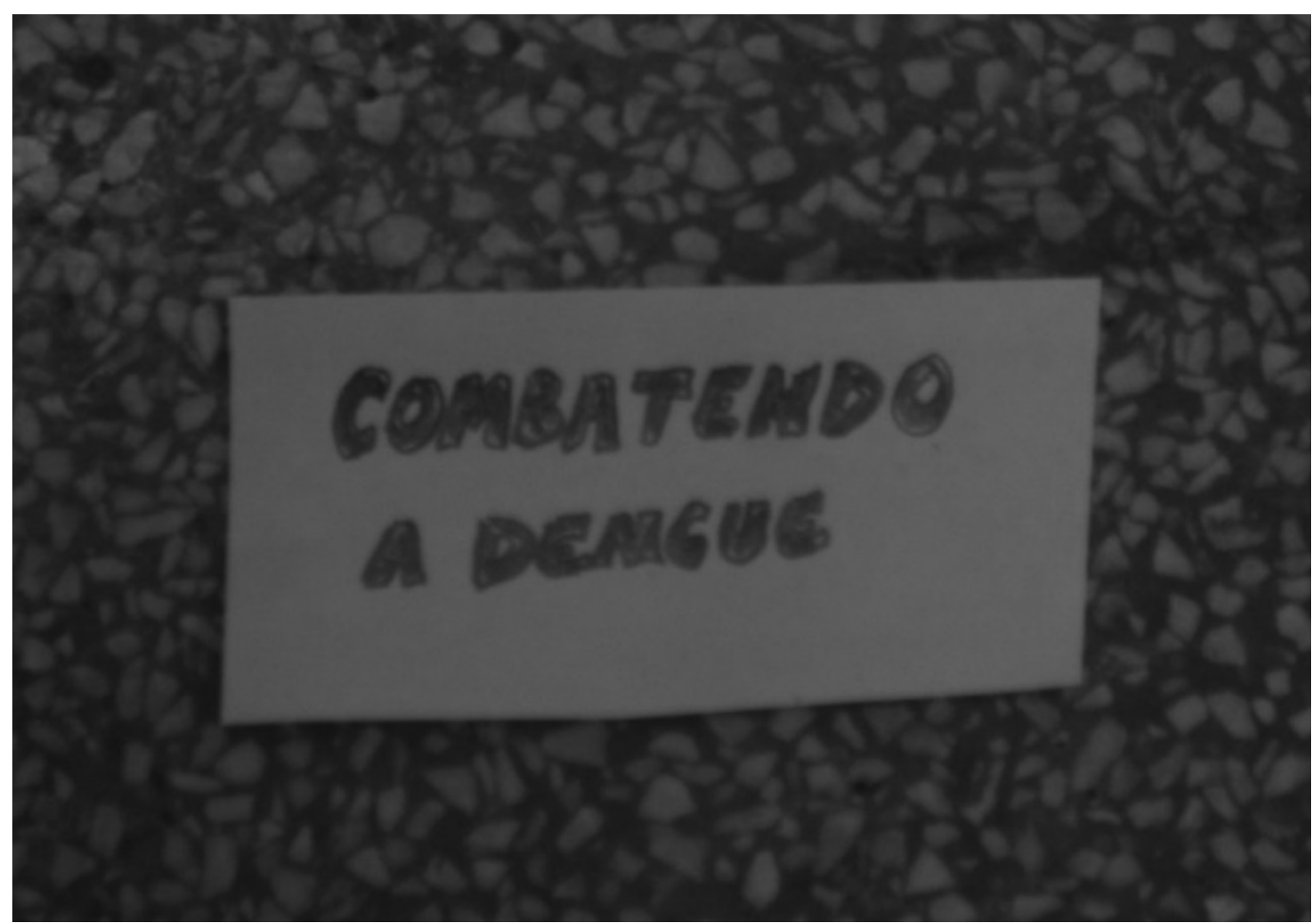

Fonte: Acervo pessoal. 
Por fim, é importante destacar que:

Toda representação visual é uma projeção imaginária do sujeito sobre um objeto, mesmo aquela que se pretende fundamentada no registro dado. A fotografia faz parte também do campo da imaginação. No jogo de revelar e ocultar, constitui-se uma dialética da construção da imagem do mundo, do homem e de seus dilemas, a doença e a morte. As imagens e o imaginário da doença e da cura, as representações sobre a vida e a morte, os olhares sobre a cidade e a convivência urbana, a problematização das instituições de auxílio à pobreza, das desigualdades sociais, entre outras, sofreram acentuada influência das epidemias. (KOURY, 2001, p. 14).

Ressalte-se o potencial da CienciArte para o pensar no desenvolvimento de propostas educativas diferenciadas, que através de suas características possibilitam o (re)pensar sobre a realidade e a busca por soluções criativas. Além do mais, as atividades realizadas também contemplaram os pressupostos da CienciArte no que se refere às 13 categorias cognitivas expressas no processo criativo de cientistas e artistas. (ROOT-BERNSTEIN, 2001).

\section{CONCLUSÃO}

O trabalho evidenciou que a proposta estimulou o trabalho em grupo, sensibilizou os integrantes das oficinas para a participação social, a integração de diferentes atores socais na busca pela mitigação de problemas complexos como os que envolvem as doenças negligenciadas e a elaboração de estratégias que dialoguem com a população de forma mais próxima.

O processo criativo desenvolvido aguçou a escuta e o olhar ampliado para o tema de interesse. No entanto, verificamos também que fragmentos de processos educativos e comunicacionais de estratégias padronizadas e tradicionais ainda estão presentes nas produções visuais dos participantes das oficinas.

\section{REFERÊNCIAS}

ACADEMIA BRASILEIRA DE CIÊNCIAS. Doenças negligenciadas. Rio de Janeiro: Academia Brasileira de Ciências, 2010. Disponível em: www.abc.org.br/IMG/pdf/doc-199.pdf. Acesso em: 14 out. 2011.

ARAÚJO-JORGE, T. C. et al. CienciArte $@$ no Instituto Oswaldo Cruz: 30 anos de experiências na construção de um conceito interdisciplinar. Ciência e Cultura, Campinas, v. 70, n. 2, p. 25-34, abr./jun. 2018.

ASSIS, S. S. Programa Saúde na Escola (PSE): contribuições para a integração de estratégias envolvendo as doenças negligenciadas e o Plano Brasil sem Miséria. 2017, 229 f. Tese (Doutorado em Ensino em Biociências e Saúde) - Instituto Oswaldo Cruz, Fundação Oswaldo Cruz, Rio de Janeiro, 2017.

ASSIS, S. S. Análise de livros didáticos, materiais impressos e das percepções e práticas dos professores e profissionais de saúde: subsídios para a estratégia integrada de prevenção e controle da dengue. 2012, 239 f. Dissertação (Mestrado em Ensino em Biociências e Saúde) - Instituto Oswaldo Cruz, Fundação Oswaldo Cruz, Rio de Janeiro, 2012.

ASSIS, S. S.; PIMENTA, D. N.; SCHALL, V. T. Materiais impressos sobre dengue: análise e percepções de profissionais de saúde e educação. Revista Brasileira de Pesquisa em Educação em Ciências, São Paulo, v. 13, n. 3, p. 25-51, set./dez. 2013.

ASSIS, S. S.; SCHALL, V. T.; PIMENTA, D. N. As representações visuais da dengue em livros didáticos e materiais impressos. RECIIS - Revista Eletrônica de Comunicação, Informação e Inovação em Saúde, Rio de Janeiro, v. 7, n. 3, n.p., jul./set. 2013.

BARBOSA, A.; CUNHA, E. T. Antropologia e imagem. Rio de Janeiro: Jorge Zahar, 2006. 
BRASIL. Ministério da Saúde. Portaria No 2.488, de 21 de outubro de 2011. Disponível em: http:// bvsms.saude.gov.br/bvs/saudelegis/gm/2011/prt2488_21_10_2011.html. Acesso em: 25 abr. 2019.

DE MEIS, L.; RUMJANEK, V. A ciência que incorpora a arte. In.: ARAÚJO-JORGE, T. (org.). Ciência e arte: encontros e sintonias. Rio de Janeiro: Senac, 2004. p. 154-169.

GAZZINELLI, M. F. et al. Educação em Saúde: conhecimentos, representações sociais e experiência da doença. Cadernos de Saúde Pública, Rio de Janeiro, v. 21, n. 1, p. 200-206, jan./fev. 2005.

HARRINGTON, A. Art and social theoris - sociological arguments in esthetics. Cambridge: Polity Press, 2004.

KOURY, M. G. P. Introdução. In.: Koury, M. G. P. (org.). Imagem e memória: ensaios em antropologia visual. Rio de Janeiro: Garamond, 2001. p. 151-171.

JOLY, M. Introdução à análise da imagem. Campinas: Papirus, 2008.

MINAYO, M. C. S. O desafio do conhecimento: pesquisa qualitativa em saúde. São Paulo: Hucitec, 2010.

OMS. Global vector control response 2017-2030. Geneva: WHO. 2017.

OMS. Sustaining the drive to overcome the global impact of neglected tropical diseases: second WHO report on neglected diseases. Geneva: WHO, 2012.

PIAULT, M. H. Real e ficção: onde está o problema? In.: KOURY, M. G. P. (org.). Imagem e memória: ensaios em antropologia visual. Rio de Janeiro: Garamond, 2001. p. 151-171.

REIS, D. C. Educação em saúde: aspectos históricos e conceituais. In.: GAZZINELLI, M. F.; REIS, D. C.; MARQUES, R. C. (orgs.). Educação em saúde: teoria, método e imaginação. Belo Horizonte: UFMG, 2006. p. 19-24.

ROOT-BERNSTEIN, R. et al. Centelhas de gênios: como pensam as pessoas mais criativas do mundo. São Paulo: Nobel, 2001.

SAWADA, A. C. M. B.; ARAÚJO-JORGE, T. C.; FERREIRA, R. Cienciarte ou ciência e arte? Refletindo sobre uma conexão essencial. Educação, Artes e Inclusão, Florianópolis, v. 13, n. 3, p. 158-177, set./ dez. 2017.

SOBRAL, M. F. F.; SOBRAL, A. I. G. P. Casos de dengue e coleta de lixo urbano: um estudo na Cidade do Recife, Brasil. Ciência \& Saúde Coletiva, Rio de Janeiro, v. 24, n. 3, p. 1075-1082, mar. 2019.

SPINK, M. J.; MENEGON, V. M.; MEDRADO, B. Oficinas como estratégia de pesquisa: articulações teórico-metodológicas e aplicações ético-políticas. Psicologia \& Sociedade, [s. l.], v. 26, n. 1, p. 32-43, jan./abr. 2014.

SOUZA, K. R. et al. Saberes e práticas sobre controle do Aedes aegypti por diferentes sujeitos sociais na cidade de Salvador, Bahia, Brasil. Cadernos de Saúde Pública, São Paulo, v. 34, n. 5, p. 1-13, maio 2018. DOI: 10.1590/0102-311X00078017

STANDLEY, C. et al. Organization of oversight for integrated control of neglected tropical diseases within Ministries of Health. PLos - neglected tropical diseases, Berkeley, v. 12, n. 11, p. 1-14, nov. 2018.

ZUIM, R. C. B.; TRAJMAN, A. Itinerário terapêutico de doentes com tuberculose vivendo em situação de rua no Rio de Janeiro. Physis: Revista de Saúde Coletiva, Rio de Janeiro, v. 28, n. 2, p. 1-19, abr./ jun. 2018. DOI: http://dx.doi.org/10.1590/S0103-73312018280205 